\title{
Coronary artery arteriovenous malformation
}

Yaron D. Barac, MD, PhD, Carmelo A. Milano, MD, and Joseph W. Turek, MD, PhD

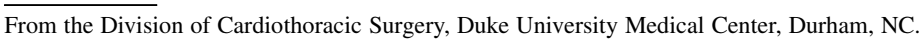

Disclosures: Authors have nothing to disclose with regard to commercial support.

Received for publication June 25, 2018; revisions received Aug 23, 2018; accepted for publication Sept 26, 2018; available ahead of print Nov 14, 2018.

Address for reprints: Yaron D. Barac, MD, PhD, Duke University Medical Center, 10 Duke Medicine Cir, Durham, NC 27710 (E-mail: yaron.barac@duke.edu).

J Thorac Cardiovasc Surg 2019;157:e203-4

$0022-5223 / \$ 36.00$

Copyright (c) 2018 by The American Association for Thoracic Surgery

https://doi.org/10.1016/j.jtcvs.2018.09.111

V Video clip is available online.

A 58-year-old woman with a history of giant coronary artery to coronary sinus fistula, status after an attempted surgical closure 11 years ago, presented with worsening dyspnea and dilated cardiomyopathy. Diagnostic workup with

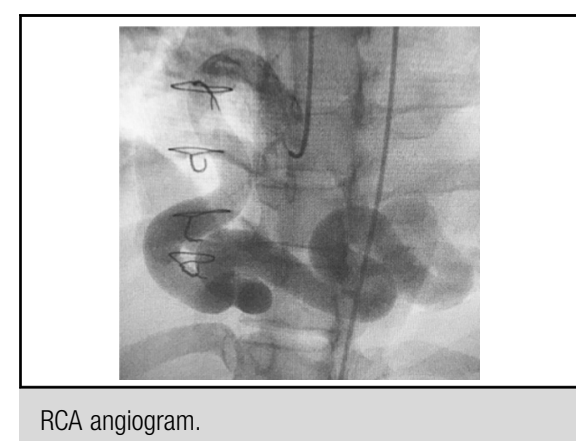

Central Message

Longstanding Coronary artery to coronary sinus bilateral fistulae can induce heart failure symptoms but can be surgically closed adequately with good clinical outcome.

See Commentary page e205.

cardiac catheterization and computed tomographic angiography revealed a high output circulation with persistent right
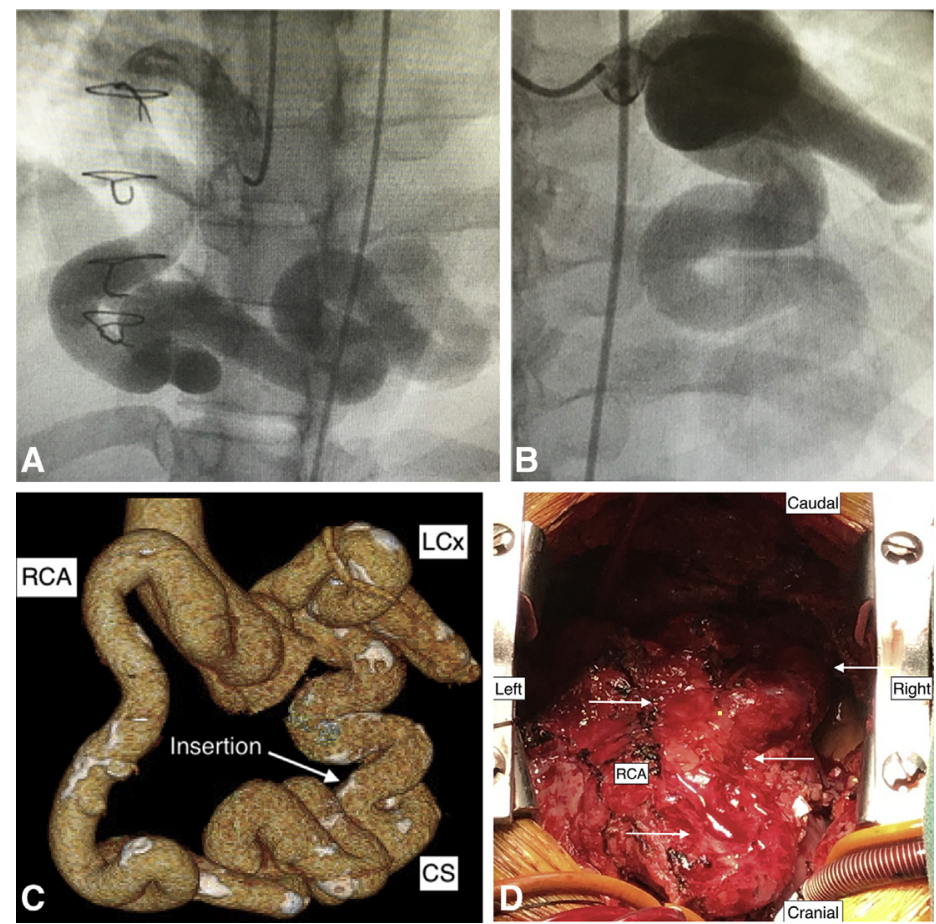

FIGURE 1. The torturous and extremely dilated coronary arteries are shown using angiogram. A, Right coronary artery (RCA). B, Left circumflex coronary artery $(L C x)$. C, 3-D computed tomography imaging reconstruction of the RCA and LCx and their insertion point to the coronary sinus $(C S)$ are depicted. D, A picture taken from the anesthesiologists' position depicts the RCA fistula width and location on the heart; the arrows point the course of the right coronary artery. 


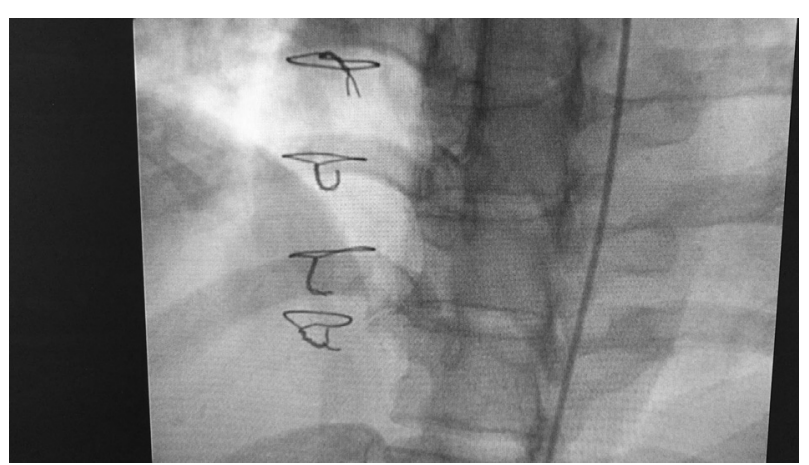

VIDEO 1. RCA angiogram. Video available at: https://www.jtcvs.org/ article/S0022-5223(18)32777-6/fulltext.

and left coronary fistulae (Figure 1, Videos 1 and 2). Reoperation was undertaken with right axillary and femoral venous peripheral cannulation for cardiopulmonary bypass because of the retrosternal, massively dilated coronary fistulae. Cardioplegic arrest was achieved using antegrade cardioplegia that was delivered at very high flow with a finger placed on the coronary sinus to prevent it from flowing directly into the coronary sinus circulation as well as retrograde cardioplegia. Next, the fistula was addressed; the dilated right coronary artery was opened longitudinally near the fistulous connection and the right atrium was

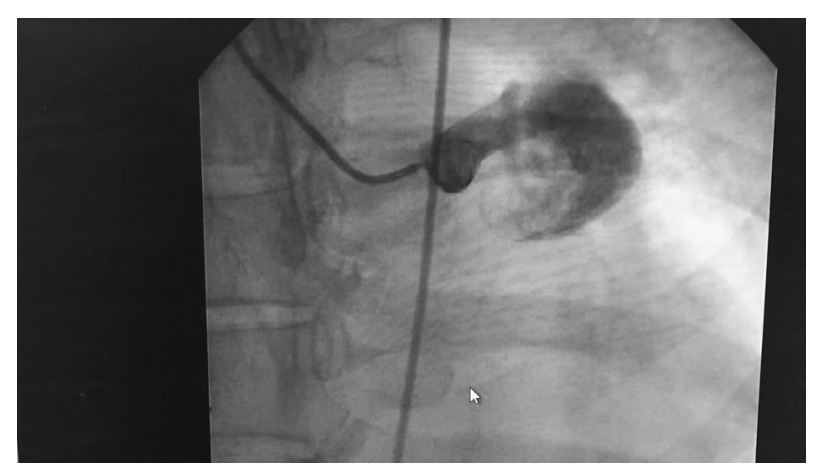

VIDEO 2. LCx angiogram. Video available at: https://www.jtcvs.org/ article/S0022-5223(18)32777-6/fulltext.

entered and a probe was inserted through the coronary sinus into the common opening to the right and left coronary fistulae. The opening was approached from the epicardial surface and was oversewn using 4-0 prolene. Furthermore, the terminal aspects of the right and left fistula near the coronary sinus were dissected, encircled, and tied off using number 4 silk suture. At the end of the procedure the mixed venous saturation of the patient came down to $82 \%$ from $99 \%$. The patient recovered well and her heart failure symptoms resolved. 